\title{
CAESAREAN SECTION IN THE MALTESE ISLANDS
}

\author{
by \\ C. SAVONA-VENTURA *
}

Medical advances have had a major impact on obstetrics, resulting in a marked decrease in mortality and morbidity, particularly in the last century. The reasons for this decline in maternal and perinatal deaths are many, but an increase in the incidence of Caesarean sections has been suggested as a contributory factor. The Caesarean operation has long had its opponents. Among the earliest was J. F. Sacombe (1750-1822) who founded the "Sacombe École anti-Césarienne", which had as its symbol a figure of Hercules slaying the hydra and the inscription "No more Caesarean section". ${ }^{1}$ In spite of continuing opposition to the operation, it appears that the Caesarean hydra has not only survived Sacombe's opposition but has also developed heads which were non-existent in his day.

The first Caesarean section on a live woman in Malta was performed at the end of the nineteenth century. Prior to this, all the recorded operations were post-mortem. During the last fifty years delivery by Caesarean section in the Maltese Islands has increased, and there has been a parallel improvement in maternal and perinatal mortality statistics. This study reviews the history of Caesarean section in the Maltese Islands in the light of fluctuations in the population and changes in the maternity services available. It also correlates the Caesarean section rates of the last fifty years with perinatal and obstetric statistics in an attempt to identify the contribution of delivery by section to the fall in mortality rates.

For this purpose I have drawn on the obstetric statistics of the last fifty years using the biennial average starting from 1937-38, as well as data from the governmentmanaged hospitals in Malta and Gozo which is in the annual reports of the Department of Health, ${ }^{2}$ supplemented by information from the labour ward Birth and

* C. Savona-Ventura, MD, MRCOG, Department of Obstetrics and Gynaecology, St Luke's Hospital, G'mangia, Malta.

This study was supported by a Foundation Grant given jointly by the British Medical Association (Malta Branch) and BUPA.

\footnotetext{
${ }^{1}$ H. R. Spencer, 'Some changes in obstetric practice', Lancet, ii: p. 817-21.

2 Annual report on the health conditions of the Maltese Islands and on the work of the Medical and Health Department for the year 1937-38, Malta, Govn. Printing Office, 1938-39, 2 vols.; Report on the health conditions of the Maltese Islands and on the work of the Medical and Health Department including the Emergency Medical Services for the years 1946-47, Malta, Govn. Printing Office, 1947-48, 2 vols.; Report on the health conditions of the Maltese Islands and on the work of the Medical and Health Department for the years 1951-1971, Malta, Govn. Printing Office, 1953-1972, 21 vols.; E. S. Grech and C. Savona-Ventura, The obstetric and gynaecological service in the Maltese Islands: 1987, Malta, St Luke's Hospital, 1988. A number of hospitals served as government-run hospitals in Malta and Gozo throughout the years under
} 


\section{Savona-Ventura}

Operation Registers of the hospitals, ${ }^{3}$ together with published demographic data for the Maltese Islands. ${ }^{4}$ I obtained additional information from the religious-run hospitals: St Catherine of Siena Hospital (1961-1980), Zammit Clapp Hospital (1971-1980), and St Dominic's Clinic (1974-1976). Data was unfortunately not available for the early years of Zammit Clapp (1911-1971) or for the military and naval hospitals: David Bruce Military Hospital (1920-1976) and King George V Hospital $(1922-1967){ }^{5}$

\section{CAESAREAN SECTION IN PRE-TWENTIETH-CENTURY MALTA}

Before 1891 Caesarean section in Malta was apparently limited to instances in which the pregnant woman died before giving birth. Post-mortem Caesarean section was a matter of concern for the medical profession and the clergy in Europe during the eighteenth century, and both the State and Church authorities enacted decrees requiring the operation to be performed so as to save the life of the foetus and ensure its baptism. The Maltese Islands have a long-standing Roman Catholic tradition which was maintained and respected even after they came under British rule with its contrasting predominantly Protestant tradition. The ecclesiastical authorities in Malta have thus for centuries been influential in civil matters. As early as 1575, Maltese midwives required a licence to practise from the Episcopal Curia, subject to a regular examination by the parish priest to assess whether the midwife was sufficiently versed in the administration of the sacrament of baptism. This licence remained a requirement until 1906. ${ }^{6}$ An example of such an examination is recorded for 1798 , when the parish priest of a village in Malta testified that the midwife, Maria Calleja, had answered satisfactorily the questions put to her about the rites of baptism, abortions and Caesarean section. ${ }^{7}$ On 14 June 1788, Archbishop Fra Vincenzo Labini of Bitonto, Italy (1780-1807), published an edict to enforce the obligation to perform postmortem Caesarean section. ${ }^{8}$ Parishioners were ordered on pain of excommunication to inform the parish priests of pregnant women who were in danger of losing their lives. Those who provided such information, or helped in any way, were granted an

study. Malta: The Central Hospital (pre-1940), Cini Hospital (1940-1949), St Luke's Hospital (1949-1981) and Karin Grech Hospital (post-1981); Gozo: Victoria Hospital (pre-1975), Craig Hospital (post-1975).

${ }^{3}$ Gozo hospital archives: register of admissions to maternity ward:Victoria Hospital, Gozo, 3 vols., 1940 to 1953; Gozo hospital archives: register of deliveries in labour ward: Victoria Hospital, Gozo, 3 vols., 9 January 1956 to 12 November 1973; Malta hospital archives: register of deliveries in labour ward: St Luke's Hospital, Malta, 5 June 1950 to 26 January 1953, vols B, C, 1; 7 December 1955 to 2 April 1958, vols 7-12; 25 November 1961 to 5 March 1963, vols 22-25; 18 November 1965 to 5 April 1968, vols 35-43; 5 July 1971 to 7 February 1973, vols 60-70; January to December 1976, 8 vols; and January-December 1983, 12 vols. Malta Hospital archives: register of operations in labour ward: St Luke's Hospital, Malta, 2 January 1981 to 31 May 1984, 1 vol.

${ }^{4}$ Demographic review of the Maltese Islands for the years 1960-89, Malta, Central Office Statistics, 1961-90, 30 vols.

${ }_{5}^{5}$ Register of deliveries in maternity division: St. Catherine of Siena Hospital, Malta, (letter from E. Attard); Register of deliveries in maternity division: St. Dominic's Hospital, Gozo, (letter from P. Attard). Register of deliveries in maternity division: Zammit Clapp Hospital, Malta, (letter from S. Crehan).

$6 \mathrm{P}$. Cassar, The Maltese midwife in history, Malta, Midwives Association, 1978, pp. 10-12.

${ }^{7}$ Curiae Episcopalis Melitensis AO 693, ff. 115r-125v; F. Ciappara, Marriage in Malta in the late eighteenth century, Malta, Associated News (M) Ltd, 1988, pp. 105-6.

${ }_{8}$ Archiepiscopal Archives Melitensis: Edicta Labini, ms. vol. 12, fol. 175r; The Malta Times, 10 October 1867 , p. 2; L'Ordine, 11 October 1867 , p. 3. 


\section{Caesarean section in the Maltese Islands}

indulgence of forty days. Parish priests were to ensure that a Caesarean section was performed by securing the services of "a surgeon or, in his absence, a physician, a midwife, a barber or another person who wanted and knew how to carry out" the operation. In the absence of a capable person, the parish priest was obliged to perform it himself.

In 1802, the regulations of the Civil Hospital in the capital, Valletta, made it obligatory for the principal or senior surgeon "to render his assistance in difficult deliveries and to perform the Caesarean operation when required". 9 It is uncertain whether the operation was to be performed on the living or only on the dead. In his series of lectures to medical students dated 1804, Dr Francesco Butigiec ${ }^{10}$ dealt extensively with the history of Caesarean section on the living and reviewed the merits and weaknesses of the arguments of various authors for and against the operation. He recommended it to save the lives of both mother and child when vaginal delivery was considered impossible. He also advised it in cases of extra-uterine pregnancy, tumours in the pregnant uterus, and extrusion of the foetus into the abdominal cavity after uterine rupture. He commented that "thanks to the sound knowledge obtained from modern anatomical studies and confirmed by authoritative rational observations, many unfortunate mothers have been saved from the cruel jaws of death together with their babies". The advances in physiological and anatomical concepts show "how barbarous were the precepts of past obstetricians who taught that in an impossible delivery the life of the mother was to be spared in preference to that of the foetus ... without considering the availability of the means, gained by experience, leading to the conservation of the lives of the two individuals". The operative procedure was also described. The uterus was incised anterolaterally avoiding injury to the Fallopian tubes, the round ligaments and the main branches of the adjoining blood vessels. After extraction of the foetus and placenta, the uterus was left unsutured, but the abdominal wall incision was closed by waxed thread stitches. Dr Butigiec believed that with this technique there was no permanent damage to the uterus and referred to cases published abroad where multiple sections had been performed with satisfactory results. However, he advised that after getting the woman's consent and encouraging her to receive the sacraments, the practitioner should obtain a second medical opinion so that, if the operation was not attended "by a happy result, the surgeon could defend himself against an accusation of incompetence". It is not known whether Dr Butigiec ever carried out the operation himself.

The first documented post-mortem Caesarean section in Malta was performed on 13 December 1780. The woman concerned was a 23-year-old passenger on a ship, in the eighth month of her pregnancy, who died from malignant fever. The operation was performed by Fedele Zammit, the assistant surgeon, who had been sent to the quarantine hospital to attend the woman and to be in readiness "to open the body in

\footnotetext{
${ }^{9}$ Piano per il regolamento dell'ospedali di Malta, Malta, 1802, p. 13.

${ }^{10} \mathrm{~F}$. Butigiec, Trattato dell'arte ostetrica dettato e spiegato del Perille Signor Dr Francesco Butigiec nello studio publico del Grand Ospedale Nazionale di' Malta. Principiato li 18 Ottobre 1804, manuscript, 1804, in P. Cassar, 'Teaching of midwifery in Malta at the beginning of the nineteenth century', St Luke's Hospital Gazette, 1973, 8(2): 91-111.
} 


\section{Savona-Ventura}

the event of the patient's death and save the baby if possible". A male child was born alive, but died after an hour. ${ }^{11}$ Another instance is recorded during the plague of 1813 when a senior Health Guard at the quarantine hospital in Malta "opened the body of a dead pregnant woman, under the direction of the physician, to enable the infant to be baptised". ${ }^{12}$ During the cholera epidemic of 1837 Dr G. M. Stilon "never neglected" to perform Caesarean sections on dead pregnant women, ${ }^{13}$ while Dr T. Chetcuti records the extraction by Caesarean section of three living foetuses "who were immediately baptised by the chaplain". ${ }^{14}$ In 1855, Dr G. La Ferla described another instance of a post-mortem section on a multipara with a very bad obstetric history in which her pregnancies had all terminated in stillborn premature infants. The mother died during her ninth pregnancy. At birth the infant had signs of life, but died soon after. ${ }^{15}$

A controversy arose during the cholera epidemic of July 1867 when two police physicians practising in the capital city and a rural village refused to perform post-mortem Caesarean sections on two pregnant women who had died from cholera, because they adhered to a school of thought which held that, in cholera cases, the foetus pre-deceased the mother. ${ }^{16}$ During the epidemics of the nineteenth century, cholera in a pregnant woman commonly brought on premature labour resulting in the birth of a stillborn child. However, foetal death prior to delivery was not inevitable. ${ }^{17}$ As a consequence of the two cases reported above, the Archbishop, Mgr Fra Gaetano Pace Forno (1857-1875), issued a circular to parish priests in which he reminded the clergy that it was their duty to order medical practitioners to perform Caesarean operations whenever necessary so that no opportunity was lost of saving the offspring, or at least of ensuring that it received baptism. He also reiterated that when no physician was willing to perform the operation, the clergy were bound to call in a midwife or another expert person, or to perform it themselves. ${ }^{18}$ The Archbishop's decree gave rise to a dispute over how reliable a non-professional's judgement could be in determining whether or not death had occurred. Furthermore, doubts were expressed as to the legality of opening up a corpse immediately after death, particularly by a non-professional, since Maltese law prohibited burials during the twenty-four hours after apparent death. ${ }^{19}$ Following the circular, post-mortem Caesarean sections on mothers succumbing to cholera were performed by medical practitioners only. Within eight days, three post-mortem Caesarean operations on cholera victims were

11 National Library of Malta: Registri degli arrivi di bastimenti in quarantina. Arch 6531, fol. 69t, 11.12.1780, fol. 74t, 11.12.1780, fol. 76, 13.12.1780; P. Cassar, 'Clinical case histories and postmortem reports from the Malta Lazaretto in the 18th century', Medi-scope, 1989, 13: 9-13.

12 W. H. Burnell, Appendice Va al secondo rapporto sulla quarantina, London, Eyre and Spottiswoode, 1855 , p. 49.

${ }_{13}$ G. M. Stilon, Sul cholera morbus, Malta, Izzo, 1839, p. 6.

14 T. Chetcuti, Notizie storiche-patologiche sul cholera, Malta, L. Tonna, 1838, p. 18.

15 G. La Ferla, Sull'uso della gomma-resina d'asa foetida adoperata per prevenire la morte del feto nelle gravidanze morbose cagionate da inerzia dell'utero, Malta, S. G. Vassalli, 1855, pp. $20-2$.

${ }_{16}$ Il Portafoglio Maltese, 7 September 1867, p. 2; 9 October 1867, p. 2; The Malta Times, 3 October 1867, p. 2; P. Cassar, 'The Church on Caesarean section in Malta in 1867', St. Luke's Hospital Gazette, 1969, 4(1): 48-52.

17 O. Spiegelberg, A textbook of midwifery, London, New Sydenham Society, 1888, vol. 1, pp. 354-5.

18 L'Ordine, 4 October 1867, p. 3; The Malta Times, 10 October 1867, p. 2; Cassar, op. cit., note 16 above.

19 The Malta Times, 10 October 1867, p. 2; 24 October 1867, p. 1; Cassar, op. cit., note 16 above. 
recorded with the extraction of live infants. ${ }^{20}$ There are no records of specific instances where Caesarean sections were performed by midwives, parish priests or lay people, though it is known that there were curates and midwives capable of performing the operation successfully in accordance with the rules of surgery. ${ }^{21}$ As late as 1883, Prof. S. L. Pisani in his lectures to student midwives told them that they had to be prepared to perform the operation on dead pregnant women in the absence of a doctor. $\mathrm{He}$ added that the operation could be performed as a last resort on a live woman as an alternative to embryotomy, and that a number of such operations had been performed successfully, but he did not state whether these had taken place in Malta. ${ }^{22}$ It is not known whether Prof. Pisani, who occupied the Chair of Midwifery at the University of Malta (1858-1880), ever performed the operation on a live woman, but he is recorded as having carried out a post-mortem section during the 1867 cholera epidemic on a woman who had died of the disease while in the fourth month of pregnancy; "the foetus outlived the mother for seven minutes and received baptism". 23

During the nineteenth century there was a widespread desire amongst obstetricians to avoid craniotomy in cases of women with contracted pelvises. This brought about an increasing acceptance of Caesarean section in spite of its high maternal mortality rate, and initiated a medico-moral controversy between Catholic and Protestant medical schools of thought, the former favouring the infant, the latter the mother. To a lesser extent, these two views were evident in Roman Catholic Malta. The first mention of them was made in 1804 by Dr Butigiec who appears to have been much influenced by French medical ideas, although he was also conversant with British authors. He was strongly in favour of Caesarean section, though he did include a number of embryotomy instruments in his armamentarium. ${ }^{24}$ During the nineteenth century in Malta, medical thought veered towards British medical practice, though Maltese practitioners remained in touch with French medical ideas. Prof. Pisani furthered his medical studies at the University of Edinburgh under Prof. J. Y. Simpson. The British influence was also promoted by contacts with British doctors who worked in Malta, such as Dr T. Spencer Wells who practised in the British garrison in the mid-nineteenth century. In 1880, Dr G. F. Inglott discussed, from a medical and moral point of view, the management of difficult labours and the merits of abortion, induction of premature labour, embryotomy and Caesarean section. He strongly advocated the last operation, emphasizing that it allowed for the survival of both mother and child. The discussion was taken up by his contemporary $\mathrm{Dr}$ B. Camenzuli who promoted craniotomy and embryotomy rather than Caesarean section. ${ }^{25}$ In 1888 , the Roman Catholic Church decided that the destruction of the child in utero was not permissible under any

20 Il Portafoglio Maltese, 9 October 1867, p. 2; 12 October 1867, p. 2; The Maltese Observer, 14 October 1867 , p. 3; L'Ordine, 11 October 1867 , p. 3; 18 October 1867, p. 3; The Malta Times, 24 October 1867, p. 1; Cassar, op. cit., note 16 above.

${ }^{21}$ Il Portafoglio Maltese, 12 October 1867, p. 2; Cassar, op. cit., note 16 above.

22 S. L. Pisani, Ktieb il qabla, Malta, P. Debono, 1883, pp. 104-5.

23 Il Portafoglio Maltese, 12 October 1867, p. 2; The Maltese Observer, 14 October 1867, p. 3; L'Ordine, 18 October 1867 , p. 3.

${ }^{24}$ Cassar, op. cit., note 10 above.

${ }^{25}$ G. F. Inglott, L'Aborto ostetrico nei suoi rapporti colla medicina e colla morale cattolica, Malta, A. Pugliseviche, 1880; B. Camenzuli, Contro-riflessioni sull aborto ostetrico, Malta, C. Busuttil, 1880. 


\section{Savona-Ventura}

circumstances. This pronouncement was repeated with papal approval in 1895. The European controversy of craniotomy versus Caesarean section continued up to the early years of the twentieth century, and was only resolved with the increasing safety of Caesarean operations. ${ }^{26}$

The first recorded Caesarean section on a live mother in Malta was performed on 28 May 1891 by Prof. G. B. Schembri on a woman who had cephalopelvic disproportion resulting from a rachitic pelvis. Both mother and child survived the surgery. Prof. Schembri occupied the Chair of Midwifery at the University of Malta (1880-1904). He had, in November 1890, performed under chloroform anaesthesia the first two laparotomies in Malta. ${ }^{27}$ The patient undergoing the first Caesarean operation was a dwarfish rachitic primigravida of 35 years. She had had her last menstrual period on 25 August 1890. Her doctor, Dr Zammit, consulted Prof. Schembri early on the morning of 28 May. Prof. Schembri examined the patient to find her cervix fully dilated in the presence of a markedly restricted rachitic pelvis. The foetus was alive. He therefore arranged for the transfer of the patient to the Central Hospital at Floriana (Malta) and at 20.00 hours, after consultations with Doctors Bonnici, Manche and Tabone, he decided in favour of a Caesarean section. Dr Cassar anaesthetized the patient, and a classical Caesarean section was performed. The eight-pound infant was born asphyxiated, but was resuscitated successfully. The uterus was sutured using silk in two layers. The patient's post-operative period was complicated by a fever of $103^{\circ} \mathrm{F}$ which came down by the sixth day. The sutures were removed on the eighth day and the patient was discharged after four weeks. ${ }^{28}$

TRENDS IN CAESAREAN SECTION DURING THE TWENTIETH CENTURY

Following this first successful Caesarean section, the operation was accepted only slowly as an alternative to vaginal delivery, so that by 1937-38, forty-five years after the first operation, Caesarean deliveries in the Maltese Islands amounted to only 0.2 per cent of total births. The rate remained similar until the 1950s when a gradual rise of about 0.4 per cent annually was noted, reaching approximately 6 per cent in the 1970s. The 1980s saw a marked rise of about 0.7 per cent annually in abdominal delivery rates reaching the 12.6 per cent level in 1986-87 (Figure 1).

During the period under review a number of hospitals contributed in varying degrees to the maternity services in Malta and Gozo. The majority of Caesarean sections were undertaken in the government-run hospitals in Malta and Gozo which served as referral hospitals for problem cases. Other hospitals which contributed towards the maternity services included those run by religious orders and the military. The religious-run hospitals (Zammit Clapp, 1911-1980, St Catherine's, 1961-1980, in Malta; and St Dominic's, 1974-1976, in Gozo) did not contribute significantly to maternity services until the 1960s and 1970s. In 1957 Zammit Clapp was reported to

${ }^{26}$ A. E. Chisholm, 'Symphysiotomy, craniotomy, and Caesarean section', Lancet, 1923, ii, 276-8.

${ }^{27}$ G. B. Schembri, 'Prima operazione cesarea', Rivista di Ostetricia e Ginecologia, 1891, reprint; V. Vella, 'Laparotomia in Malta', Rivista di Ostetricia e Ginecologia, 1891, reprint.

${ }^{28}$ Schembri, ibid.; R. Farrugia Randon, 'Notes on the history of Caesarean section', Chestpiece, 1969, 2(11): 37-9. 
Caesarean section rates \%

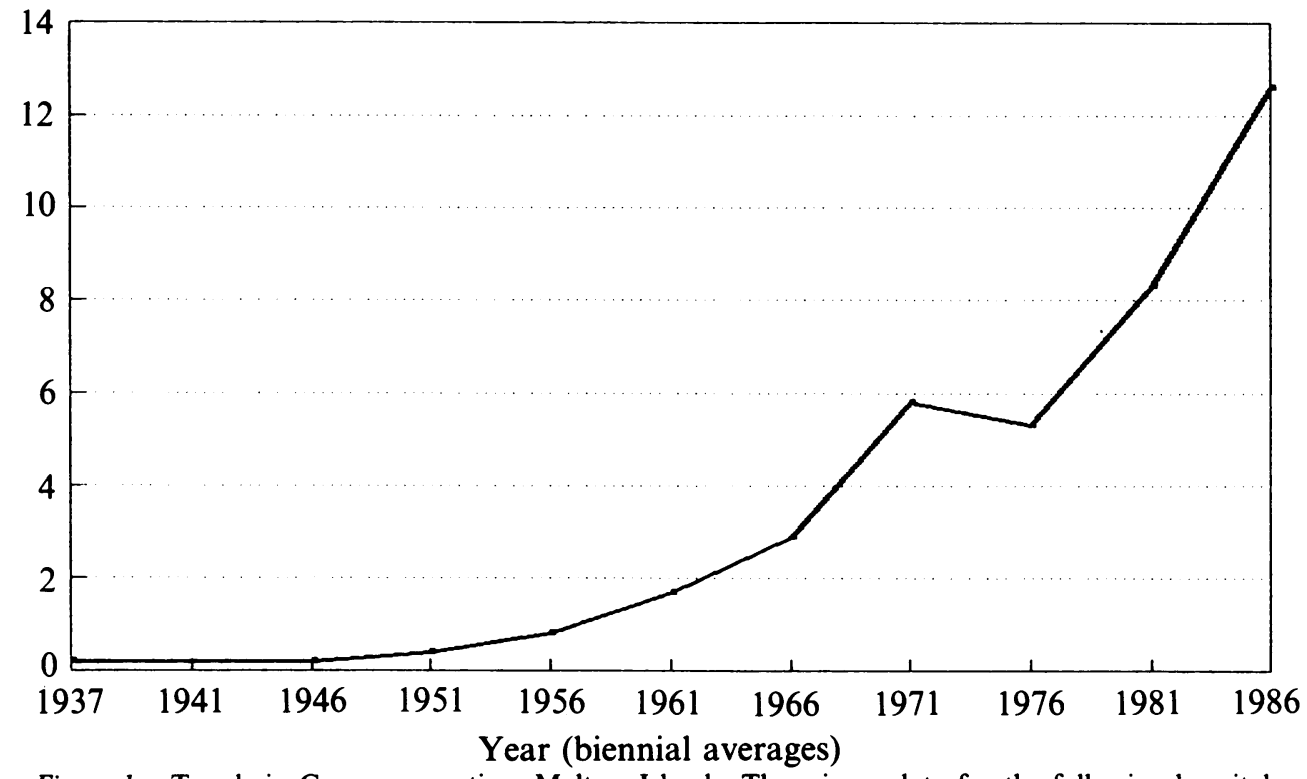

Figure 1: Trends in Caesarean section: Maltese Islands. There is no data for the following hospitals during the years indicated: King George V, 1937-38, 1951-67; David Bruce, 1937-79; Zammit Clapp, 1937-67; St Luke's 1941-42; Victoria, 1951-52, 1976-77.

be the only private hospital of any size in Malta with 15 maternity beds. ${ }^{29}$ The military-run hospitals (David Bruce Military Hospital, 1920-1976, and King George $\mathrm{V}, 1922-1967)$ were generally limited to service personnel and their families, though the King George V opened its maternity wards to the general population in the 1950s. Before 1950, mothers generally remained at home for their confinements and very few went to hospital for normal labour. ${ }^{30}$ Thus, during the period $1937-38$ only 5.9 per cent of births occurred in the government-run hospitals in Malta and Gozo, and in 1951-52 the rate increased to only 6.5 per cent. During the following years the attitude towards hospital confinement changed so that in 1955 it was noted that "whereas formerly mothers looked at maternity services with indifference, sometimes even with diffidence, they started to very willingly avail themselves of it and enjoy its benefits". ${ }^{31}$ This change is reflected by the increase in the contribution of the government-run hospitals to maternity services, accounting for 18.1 per cent of all births. The increasing rate of hospital confinements continued so that in 1961 it was estimated that 43.5 per cent of mothers were delivered in government-run hospitals, while 9.8 per cent were delivered in the remaining hospitals and 46.7 per cent in their own homes. The hospital confinement rates continued to increase during the 1970s and 1980s so that about 97 per cent of deliveries in 1986-87 took place in a hospital. ${ }^{32}$

\footnotetext{
${ }^{29}$ Reports on the medical services and a hospital building programme, Malta, Central Office of Information, 1957.

${ }^{30}$ Report . . 1951, op. cit., note 2 above.

31 Report . . . 1955, op. cit., note 2 above.

${ }^{32}$ Study Group: F.I.G.O./I.C.M., Maternity care in the world: an international survey of midwifery practice and training, Oxford, Pergamon Press, 1966; Grech and Savona-Ventura, op. cit., note 2 above.
} 


\section{Savona-Ventura}

The 1961 domiciliary confinement rate of 46.7 per cent was one of the highest rates in Europe with only Yugoslavia (53.1 per cent), The Netherlands (71.2 per cent) and Portugal ( 80.0 per cent) reporting higher levels. In the United Kingdom the rates were lower than in Malta: England and Wales 32.4 per cent, Scotland 25 per cent, and Northern Ireland 29 per cent. The Malta domiciliary confinement rate stands in marked contrast to the 2 per cent reported for Luxembourg and Gibraltar. Gibraltar catered for about only one-tenth the total number of births as compared to Malta and was strongly influenced by British medical practice and organization. Luxembourg's number of live births was approximately similar to that of the Maltese Islands. ${ }^{33}$

Table 1: ABDOMINAL DELIVERY TRENDS

\begin{tabular}{ccrrrrrrrr}
\hline Years & Total & \multicolumn{9}{c}{ Number of Caesarean sections } & & National \\
& deliveries & SLH & VH & SCH & ZCH & DBMH KG V & SDH & $\%$ \\
\hline $1937-38$ & 18,222 & 32 & 0 & - & $?$ & $?$ & $?$ & - & 0.2 \\
$1946-47$ & 23,518 & 47 & 0 & - & $?$ & $?$ & - & - & 0.2 \\
$1951-52$ & 19,163 & 75 & $?$ & - & $?$ & $?$ & $?$ & - & 0.4 \\
$1956-57$ & 17,577 & 125 & 9 & - & $?$ & $?$ & $?$ & - & 0.8 \\
$1961-62$ & 15,330 & 212 & 5 & - & $?$ & $?$ & $?$ & - & 1.7 \\
$1966-67$ & 10,681 & 201 & 6 & 99 & $?$ & $?$ & $?$ & - & 2.9 \\
$1971-72$ & 10,930 & 421 & 3 & 122 & 88 & $?$ & - & - & 5.8 \\
$1976-77$ & 11,864 & 419 & $?$ & 91 & 121 & $?$ & - & 5 & 5.4 \\
$1981-82$ & 11,533 & 912 & 49 & - & - & - & - & - & 8.3 \\
$1986-87$ & 10,847 & 1,225 & 142 & - & - & - & - & - & 12.6 \\
\hline
\end{tabular}

(SLH, VH=government-run hospitals; $\mathrm{SCH}, \quad \mathrm{SCH}, \quad \mathrm{SDH}=$ religious-run hospitals; $\mathrm{DBMH}$, KG V = military hospitals)

As the Caesarean section rate rose, so there was a definite decrease in the maternal death rate in the Maltese Islands during the 1940s (Figure 2). This was a result of a drop in deaths due to sepsis and haemorrhage from the 373.2 per 100,000 births in $1937-38$ to 78.3 per 100,000 in 1951-52. The social and medical changes that contributed to this have been previously reviewed and attributed to the greater availability of blood for transfusion and the introduction of asepsis and antimicrobials in the pre- and post-war periods. ${ }^{34}$ Caesarean section probably contributed only minimally to the lower mortality rate by reducing the incidence of prolonged labour which increases the likelihood of uterine rupture and sepsis. It seems probable that it was only up to a 2 per cent rise in the operation that the mortality rate was affected.

Caesarean sections in Malta have, in the majority of cases, been performed under general anaesthesia in hospital. The post of anaesthetist in the government-run hospital in Malta was created at the end of the First World War. The anaesthetists appointed often received postgraduate training in anaesthesia in the United Kingdom. By 1947, the number of anaesthetists in the government hospital increased to three.

\footnotetext{
${ }^{33}$ Study Group: F.I.G.O./I.C.M., ibid.

${ }^{34} \mathrm{C}$. Savona-Ventura, 'Reproductive performance on the Maltese Islands during the Second World War'. Med. Hist., 1990, 34: 164.
} 


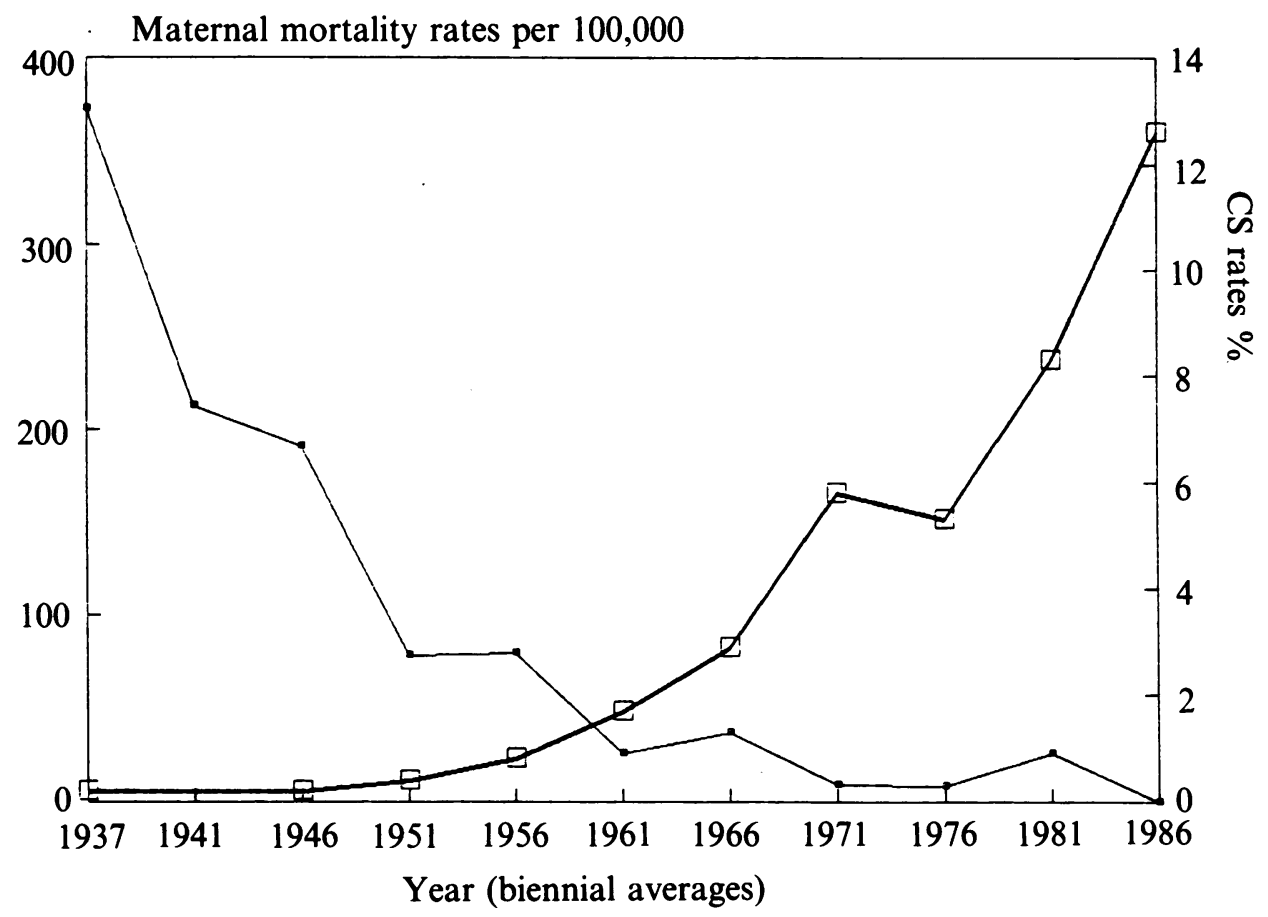

Figure 2: Maternal deaths

$\square$ CS rate

The first section under epidural analgesia was performed in $1980 .{ }^{35}$ The surgery related mortality from the operation has decreased dramatically during the period under review. In 1937-38 at the government-run hospital in Malta there were ten such maternal deaths giving an overall mortality rate of 31.3 per cent. These included seven women who died following complications of ruptured uterus, one case of postoperative tetanus, and two cases of post-operative cardiac insufficiency. One further operation was performed post-mortem on a mother who died following complications of eclampsia. The foetus was macerated. During 1951-52, surgery related mortality in the government-run hospital in Malta amounted to 2.7 per cent with only two deaths, one mother dying following complications of the ruptured uterus and the second from cardiac failure complicating acute myocarditis which followed a lower segment section for failed forceps delivery. There were also two post-mortem sections performed during these years. In 1956-57, only one 44-year-old diabetic mother (0.8 per cent) died of post-operative shock. In 1961-62 another mother ( 0.5 per cent) died from complications of severe pre-eclampsia and a concealed accidental haemorrhage. A further surgery related maternal death $(0.5$ per cent) occurred in 1966-67. During 1971-72 there were no deaths due to surgery in the hospital though two sections were performed post-mortem on mothers who died

\footnotetext{
${ }^{35}$ P. Cassar, 'History of anaesthesia in Malta', Acta Anaesth Melitensis, 1984, 1(2): 13-18; N. Bovkovski, and E. S. Grech, 'Epidural anaesthesia for elective Caesarean section', Acta Anaesth Melitensis, 1983, 1(1): 43.
} 


\section{Savona-Ventura}

undelivered from cardiac arrest during a surgically induced labour for severe pre-eclampsia, and from complications of myasthenia gravis. Both infants were born alive but died soon after. Since then, surgery related mortality has seldom occurred and there have been only three maternal deaths associated with surgery since 1975, giving an overall mortality rate (1975-1989) of 0.04 per cent. In 1978 a patient died following a primary spontaneous pneumothorax from congenital bullae during anaesthesia undertaken for an elective Caesarean section. The other two cases occurred in 1980, one caused by Mendelson's syndrome following an operation for imminent eclampsia and the other following an anaesthetic accident during elective section. There was one post-mortem section on a mother who died undelivered from amniotic fluid embolism. The infant lived for one day. ${ }^{36}$

The type of surgery has also changed during this period. During 1937-38 at the government-run hospital in Malta, the most frequent operation performed was the classical section (18 cases: 56.3 per cent), while the lower segment approach was used in 3 cases ( 9.4 per cent). There were 9 cases (28.1 per cent) of Porro Caesarean hysterectomy, and 2 (6.3 per cent) of Portes operation. The latter, involving exteriorization of the uterus after a classical section, was usually limited to those cases where sepsis was advanced or where the uterine rupture was a small one and it was desirable to preserve the uterus. The procedure facilitated repeat surgery for a hysterectomy if complications ensued. ${ }^{37}$ Ten years later, during $1946-47$, the majority of sections performed in the hospital were classical or lower segment operations accounting for 66.0 per cent of all operations. Porro Caesarean hysterectomy was performed in 2 cases (4.2 per cent), and Portes operation in 14 (29.8 per cent). The increasing use of Portes operation in preference to Porro hysterectomy probably reflects a more conservative approach in the management of cases complicated by sepsis and uterine rupture. This may well have been due to the availability of antimicrobials and the associated fall in maternal mortality from puerperal sepsis, and the easier access to blood transfusion reducing maternal mortality caused by haemorrhage. During 1951-52 the lower segment approach became the commoner operation (48 cases: 64.0 per cent), while the classical section was performed in 15 cases (20.5 per cent) and Porro hysterectomy in 12 (16.0 per cent). There were no Portes operations. By 1956-57 all Caesarean sections performed at St Luke's Hospital were lower segment approaches apart from 8 cases (6.4 per cent) which were Caesarean hysterectomies. The classical section with its long-term risks appears to have been forsaken. Subsequently, Caesarean hysterectomies were virtually abandoned, being reserved only for specific circumstances.

The period under review also saw a gradual, but marked, decrease in foetal loss as a result of stillbirths and neonatal mortality (Figure 3). Thus the stillbirth rate fell gradually from the 32.6 per 1000 total births in 1937-38 to about 10.5 per 1000 total births in 1971-72, and thereafter maintained this approximate level. The neonatal mortality rate showed a similar decline. The reasons for this are complex and controversial. It is widely acknowledged that the socio-biological characteristics of a

\footnotetext{
${ }^{36}$ C. Savona-Ventura and E. S. Grech, 'Maternal mortality in the Maltese Islands', Int. J. Gynaec. Obstet., 1987, 25: 283-90.

37 Annual report ... 1938, op. cit., note 2 above.
} 


\section{Caesarean section in the Maltese Islands}

population, together with certain extrinsic factors, are important in determining the perinatal mortality of a country. There have been marked socio-economic changes in the Maltese population since the Second World War. The fall in perinatal mortality after the 1950s has been reviewed and correlated to the decrease in family size, the organization of antenatal care, and increasing hospital confinement rates. ${ }^{38}$ Caesarean section can be regarded as a possible contributor to the improvement in perinatal statistics by allowing early intervention in situations where foetal distress and impending death are identified. Foetal indications for undertaking surgery became important after the 1960s when 20-30 per cent of all sections were undertaken for the benefit of the foetus. It appears, however, that there would be little to be gained in terms of foetal survival with Caesarean section rates greater than 6 per cent (Figure 3).

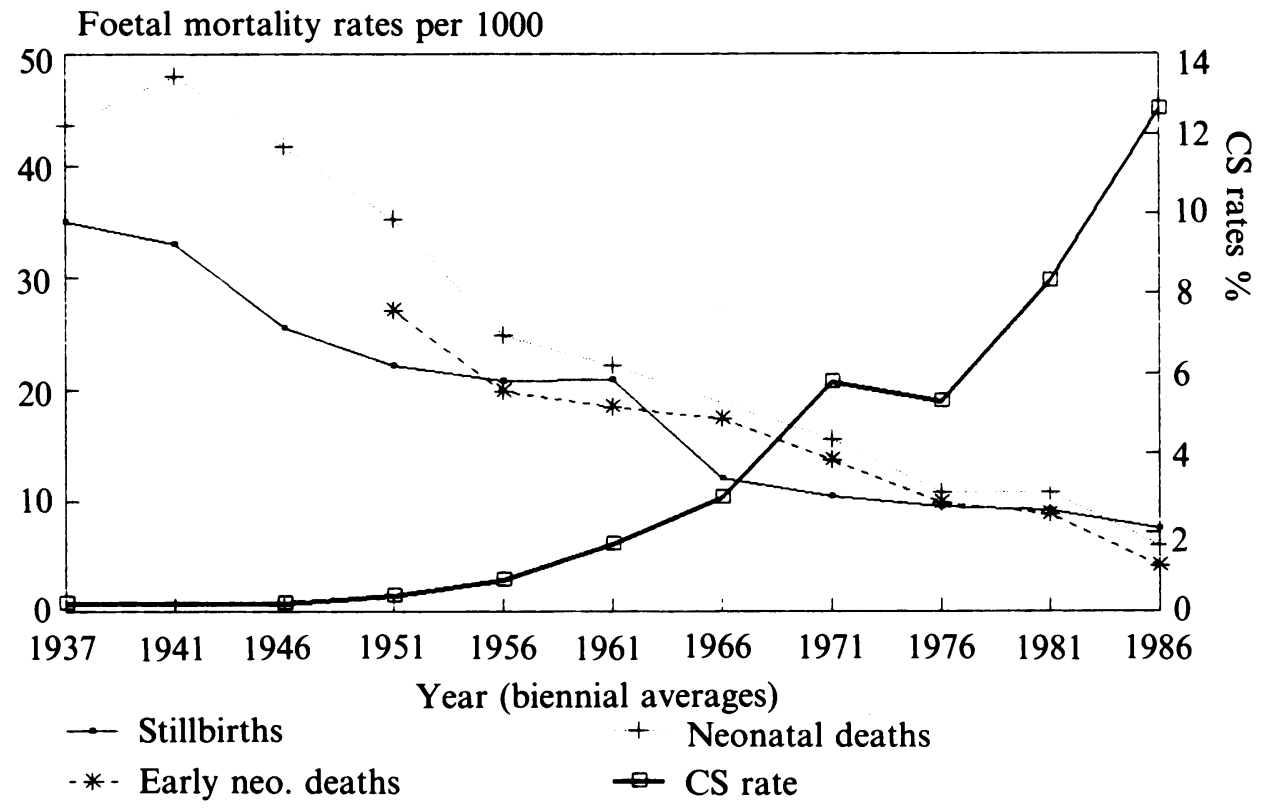

Figure 3: Foetal loss trends. There is no data for early neonatal deaths in 1937-38, 1941-42, 1946-47.

Foetal morbidity is more difficult to assess. The rising trend in Caesarean section at government-run hospitals in Malta in the last fifteen years has been associated with a minimal increase in vaginal delivery rates with the use of instruments from 3.2 per cent in 1975 to 4.4 per cent in 1989. This rise in abdominal operations and assisted vaginal delivery rates can be attributed only to an increased awareness of pregnancy and labour complications together with a more active intervention favouring the infant. This is further reflected by a marked decrease in assisted breech delivery rates of single births from 3.6 per cent in 1979 to 0.7 per cent

${ }^{38}$ C. Savona-Ventura and E. S. Grech, 'Perinatal mortality in the Maltese Islands', Int. J. of Gynaec. Obstet., 1985, 23: 25-30. 


\section{Savona-Ventura}

in 1989. More and more breech presentations are being delivered by Caesarean section. A similar change in attitude can be noted in the management of multiple pregnancy. The Caesarean section rate in twin births at St Luke's Hospital during the five years 1980-84 amounted to 10.3 per cent of all twin births and 21.3 per cent during the years 1985-89. A similar trend has been noted for births of triplets. ${ }^{39}$

The reasons for performing Caesarean operations have also changed over the years. Initially, surgery was undertaken to avoid problems with delivery and to manage cases of ruptured uterus. Thus in 1937-38 faults in the birth canal or an abnormal foetal position accounted for 24 cases ( 75.0 per cent), while ruptured uterus accounted for 7 ( 21.9 per cent). The incidence of ruptured uterus was reported in 1938 to be much too high and many patients were admitted in a moribund state as a result of mismanagement prior to reaching hospital. ${ }^{40}$ One Caesarean section was performed post-mortem on a mother who died following complications of eclampsia. The indications for undertaking Caesarean section showed marked changes fifteen years later (1951-52). While problems in delivery (54.7 per cent) and ruptured uterus (16.0 per cent) remained important reasons for abdominal delivery, foetal and maternal indications accounted for 13.3 per cent each. In 1951-52, placenta praevia constituted the most common maternal reason for Caesarean section. In 1938, it had been undertaken for placenta praevia only in primiparae with closed cervix and severe haemorrhage when there was an interest in saving the baby's life. The routine treatment then was to perform tamponage when the cervix was closed. In lateral and marginal cases, rupture of the membranes was performed and a pressure bandage applied over the abdomen. In other cases when bleeding continued, a leg was pulled down with weights after internal or Braxton-Hicks version, or Willett's forceps were applied to the caput. In 1938 there were 12 cases of placenta praevia delivered in the government-run hospital in Malta, five of these were more or less central, two marginal and five lateral. None was delivered by Caesarean section. There were no maternal deaths associated with placenta praevia, but perinatal mortality was high, with 5 stillbirths and 2 early neonatal deaths. In 1951-52, the 9 cases of placenta praevia delivered by Caesarean operations accounted for 12.0 per cent of all the sections performed at St Luke's Hospital. During the same period 3 cases of placenta praevia were delivered after application of Willett's forceps to the scalp, while the application of weight after version was used four times. Two women died as a result of haemorrhage from placenta praevia in the hospital, while there were 13 stillbirths and 2 neonatal deaths following complications of placenta praevia. ${ }^{41}$

Malpresentation accounted for another 12.0 per cent of all sections performed in the hospital in 1951-52, whereas in the previous index years of 1937-38, no operations had been carried out for this condition. Instead, internal version and breech extraction (6.4 per cent), or forceps delivery ( 8.6 per cent) were the methods used. Destructive operations on the foetus had been practically abolished (1.0 per

\footnotetext{
${ }^{39} \mathrm{C}$. Savona-Ventura and A. Zammit, 'High-order multiple births in the Maltese population', Maltese med. J., 1992, 4(1): 11-17.

40 Annual report ... 1938, op. cit., note 2 above.

${ }^{41}$ C. Savona-Ventura, 'Placenta praevia. Management in the last century', Medi-scope, 1991, 14: 5-8.
} 


\section{Caesarean section in the Maltese Islands}

cent). In 1951-52, internal version was performed in 5.8 per cent of deliveries in the hospital, forceps were used in 10.8 per cent, and destructive surgery carried out in 0.1 per cent. Repeat operations were becoming an important problem, accounting for 13.3 per cent of all sections performed. Concern for the safety of the foetus was the reason for Caesarean operations in certain cases such as elderly primigravida (5 cases), bad obstetric history (3 cases), cord prolapse (1 case) and breech presentation (1 case).

After the advent of antimicrobials and blood transfusion, death by sepsis and haemorrhage became less likely and conditions such as hypertensive disease took over as the most frequent causes of maternal deaths. ${ }^{42}$ Efforts to reduce mortality from such conditions resulted in a more active intervention policy in the management of these cases. This resulted in a greater proportion of Caesarean sections being undertaken because of the poor condition of the mother. Thus, in 1956-57 maternal factors accounted for 29.6 per cent of all sections performed at St Luke's Hospital (Figure 4), of which 12.8 per cent were due to placenta praevia, and 16.0 per cent to eclampsia or severe hypertensive disease of pregnancy. This last figure contrasted unfavourably with 1951-52 when only one Caesarean operation was performed for this reason (1.3 per cent). The number of operations undertaken for ruptured uterus fell sharply from 16.0 per cent in 1951-52 to 7.2 per cent in 1956-57. Problems with delivery and the condition of the foetus accounted for 48.0 per cent and 8.8 per cent of cases respectively. Delivery problems for this period included for the first time uterine inertia ( 3 cases: 2.4 per cent), and failed induction of labour ( 3 cases: 2.4 per cent), probably reflecting a more active intervention policy in the light of increasing hospital confinement rates and the better supervision that this allowed by comparison to domiciliary care. Foetal distress was the indication for undertaking surgery in only 5 cases ( 4.0 per cent). Breech presentation accounted for a further 5 ( 4.0 per cent), a rise from the 1.0 per cent in 1951-52.

The reasons given for undertaking Caesarean section at St Luke's Hopsital in 1961-62 showed a further rise in sections for foetal problems, particularly foetal distress and cord prolapse. This reflected greater supervision by hospital midwives and obstetricians during labour, and early diagnosis of intrapartum foetal problems. The condition of the mother accounted for 44.3 per cent of the operations, the majority for placenta praevia and severe hypertension, and three for accidental haemorrhage. There was a remarkable drop in the incidence of Caesarean section undertaken for ruptured uterus from 21.9 per cent in 1937-38 to 1.9 per cent in 1961-62 reflecting the greater awareness by general practitioners of the dangers of attempts at delivery in the patient's home in cases of prolonged labour and an increased willingness on the part of the patients to give birth in hospital if complications were identified. The reasons for undertaking section in 1967 differed very little from those in 1961-62, though problems with delivery appear more important, accounting for 53.6 per cent of cases. No sections were undertaken for ruptured uterus.

During 1972, figures from St Luke's Hospital showed a rise in Caesarean sections performed as a result of problems with delivery (55.6 per cent). Maternal factors were

\footnotetext{
${ }^{42}$ Savona-Ventura and Grech, op. cit., note 36 above.
} 


\section{Savona-Ventura}

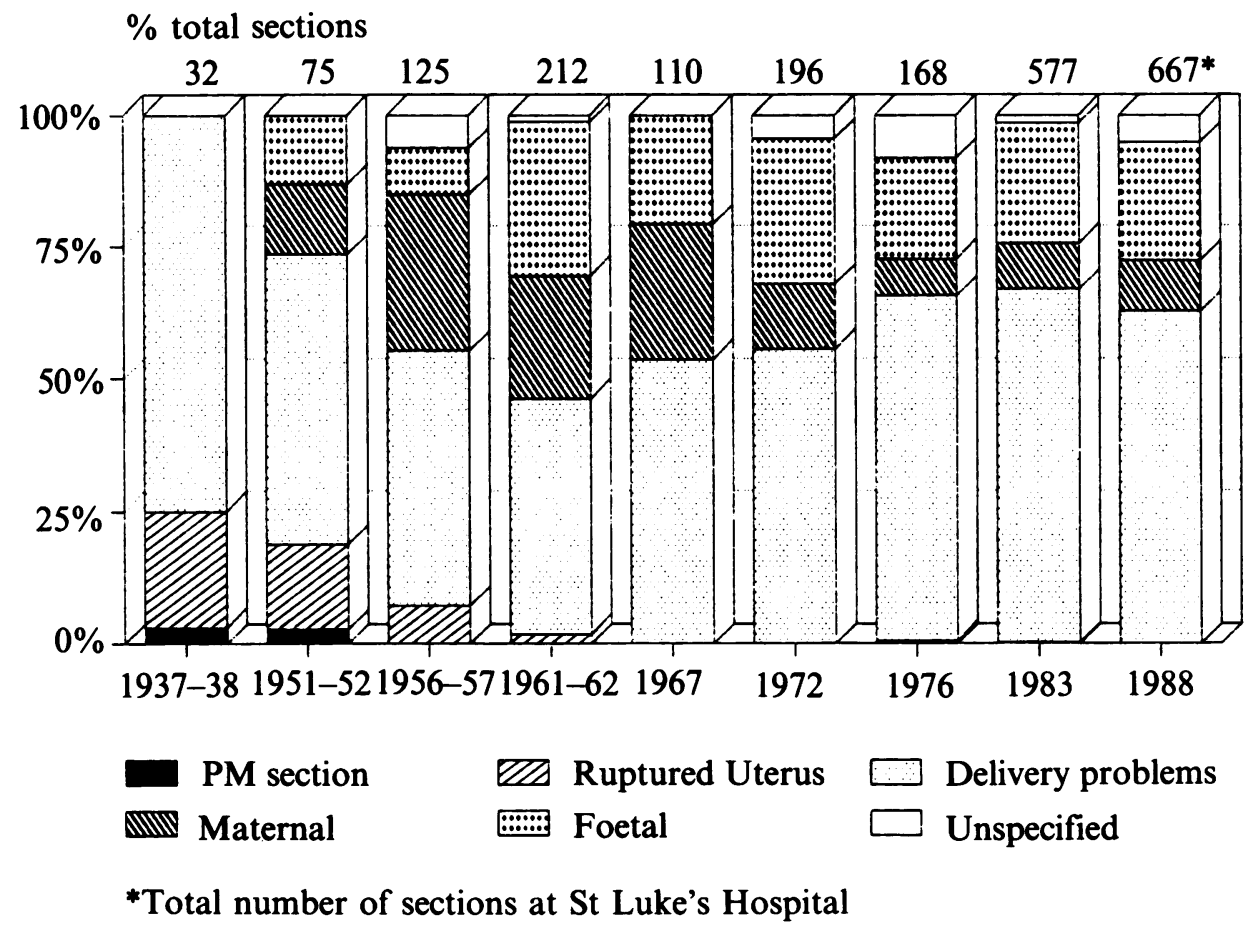

Figure 4: Caesarean section indications.

the reason for only 12.2 per cent of abdominal deliveries, probably reflecting a more active policy of induction of labour in the management of obstetric complications. Ten operations were carried out for failed induction of labour. An important proportion of 27.6 per cent were performed to resolve foetal problems. In 1976 there was a further rise in sections undertaken for problems with delivery, with a concomitant drop in those resulting from maternal indications. This change from previous years may be attributed to the increasing recourse to induction of labour in cases of hypertension and diabetes mellitus. In 1976, failed induction became a more frequent reason for Caesarean section amounting to 7.1 per cent of operations, maternal complications, excluding placenta praevia, accounting for 2.4 per cent and foetal indications for 19.1 per cent. The Caesarean operations performed in 1983 showed a proportionately greater incidence of foetal and maternal indications with a correspondingly lower number of delivery problems. However, the differences were not marked. The rise in instances of the operation being undertaken for foetal indications was due to an increase in those performed for breech presentations and because of a poor obstetric history. The reasons given for Caesarean sections in 1988 showed a similar pattern to that of the previous index year.

\section{CONCLUSIONS}

Abdominal delivery is one of the oldest operations in the history of medicine. The first authentic account of the operation on a live woman in Europe was made by 
Caspar Bauhin in 1599, in which he stated that Jacob Nufer, a sow-gelder at Siegershausen in Switzerland, opened up the abdomen and uterus of his wife about the year 1500. The first writer on Caesarean section was François Rousset, who in 1581 enumerated 15 successful cases. ${ }^{43}$ The operation was described in detail by Scipione Mercurio in 1601. A copy of the 1713 edition of Mercurio's book is available in the Malta National Library. ${ }^{44}$

For many centuries the operation was reserved as a desperate, last resort to secure the child from a dead or dying mother. The outcome for both mother and infant was almost invariably fatal, though exceptions must have occurred. This was the situation which persisted in the Maltese Islands until the end of the nineteenth century. The civil and ecclesiastical authorities in Roman Catholic Malta ensured by regular edicts and hospital regulations that women who died during pregnancy or childbirth were delivered by post-mortem Caesarean section performed by the attending physician, midwife, or even the parish priest himself. With the advent of a free press in 1839 , the problems posed by this state of affairs, provoked a controversy, which highlighted the possibility of someone medically untrained performing an operation on a woman who was still alive.

In spite of the seemingly increased popularity of the operation, opponents of Caesarean section were numerous, because of the high maternal mortality rate associated with it, a situation that prevailed until the latter half of the nineteenth century. Sam Merriman, in 1838, reported 13 recoveries out of 52 operations performed in Great Britain, while C. Kaysen, in a collected series of 338 Caesarean sections performed between 1750 and 1839, reported an overall mortality rate of 62 per cent and a hospital mortality of 79 per cent. ${ }^{45}$ This high death rate caused the morality of the operation to be questioned. Opponents of Caesarean section, who were mainly British and German, maintained that the mother's life was more important than that of the unborn child. Therefore, rather than expose the woman to the risk of death from Caesarean section they preferred to carry out a craniotomy, which was reported to have a lower maternal mortality rate of approximately 54 per cent during 1865-70 when the operation was undertaken as a last resort, and 16 per cent in the subsequent twelve years when the operation was performed in good time. ${ }^{46}$ The Roman Catholic Church, on the other hand, maintained that the destruction of the child in utero was not permissible under any circumstances. This medico-moral controversy is reflected in the comments of contemporary Maltese authors. Under British rule, in the nineteenth century, Malta upheld a strict Roman Catholic tradition. This explains why, when Malta had just been ceded to the British, Dr Butigiec found it necessary to promote Caesarean section as a method of delivery rather than embryotomy. ${ }^{47}$ This moral attitude persisted in Malta until the twentieth

${ }^{43}$ T. Cianfranni, A short history of obstetrics and gynaecology, Springfield, C. C. Thomas, 1960.

${ }^{44} \mathrm{~S}$. Mercurio, La comare o ricoglitrice, Venice, Giotti, 1713.

45 J. M. M. Kerr, R. W. Johnstone, and M. H. Phillips, Historical review of British obstetrics and gynaecology 1800-1950, Edinburgh, Livingstone, 1954, pp. 31-2; Spiegelberg, op. cit., note 17 above, vol. 2, pp. 607-25.

${ }^{46}$ Speigelberg, ibid, vol. 2, p. 583.

${ }^{47}$ Cassar, op. cit., note 10 above. 


\section{Savona-Ventura}

century. With increasing exposure to British ideas of medical practice, Maltese doctors addressed this moral controversy with $\mathrm{Dr}$ Inglott and Dr Camenzuli publishing opposing views. ${ }^{48}$

It was not until the end of the nineteenth century that advances in surgical techniques combined with Lister's antiseptic methods, resulted in a considerable decline in the death rate following abdominal delivery. In 1888 it fell to 24.8 per cent. The surgical technique which brought this about was initiated by Edward Porro in 1876 who suggested amputation of the uterus after Caesarean section with fixation of the cervical stump in the abdominal wound in an attempt to diminish the danger of sepsis and haemorrhage. ${ }^{49}$ The Porro operation went out of fashion when suturing of the uterus during Caesarean section became popular, thus enabling the uterus to be retained. Other doctors also suggested modifications in order to minimize the risk of infection. In 1906, F. Frank opened the abdomen and uterus through a transverse incision at the level of the internal os after uniting the cut edges of the parietal and visceral peritoneum to exclude the peritoneal cavity. This operation is the prototype of those performed today. ${ }^{50}$

The various modifications, combined with improvements in anaesthesia, antibiotics and easily available blood, decreased significantly maternal mortality following surgery. The fatality rate for Caesarean sections in National Health Service hospitals in the United Kingdom stood at 0.4 per 1000 Caesarean sections in 1982-84, compared with 0.5 in $1979-81,0.7$ in $1976-78,0.8$ in $1973-75$, and 1.0 in $1970-72.51$ Now the operation is increasingly performed for a wide range of maternal and foetal indications. The accelerating rise in Caesarean section rates in most hospitals in developed countries is a matter for concern. In the Maltese islands, it was only after the middle of the twentieth century that Caesarean section became a regular feature of obstetric practice with a rise in the national rate. Prior to and after the Second World War, Caesarean section was an operation undertaken in cases of obstructed labour or ruptured uterus.

Over the past fifty years there has been a gradual increase in Caesarean section rates in the western world, and it is questionable whether this rise has been attended by a proportional gain in benefits to mother and child. In the Maltese Islands there has also been a gradual rise in Caesarean section rates since the 1950s which reached the high level of 12.6 per cent in the later $1980 \mathrm{~s}$. There are many reasons for this. The increasing safety of the operation for the mother since the 1940s has made such births a practical alternative to vaginal delivery, and the initial rise in the number of Caesarean sections was a consequence of efforts to reduce perinatal mortality rates. It was maintained after the development of antenatal and intrapartum monitoring techniques which identify impending foetal demise or damage, while the advances in

\footnotetext{
${ }^{48}$ Inglott, op. cit., note 25 above; Camenzuli, op. cit., note 25 above.

${ }^{49}$ Kerr et al., op. cit., note 45 above.

$50 \mathrm{~J}$. R. Willson, 'The conquest of Caesarean section-related infection: a progress report', Obstet. Gynecol., 1986, 72(3): 519-32.

${ }^{51}$ A. Turnbull, V. R. Tindall, R. W. Beard, G. Robson, I. M. P. Dawson, E. P. Cloake, J. S. A. Ashley, and B. Botting, Report on confidential enquiries into maternal deaths in England and Wales 1982-1984, London, HMSO, 1989, p. 87.
} 


\section{Caesarean section in the Maltese Islands}

neonatal care, especially of the pre-term infant, has resulted in a greater effort to decrease intrapartum trauma to the infant by performing more Caesarean deliveries. It is now possible to recognize a much greater percentage of those cases for which a vaginal delivery is unfeasible or undesirable. Probably most foetuses now being identified as showing evidence of distress would have survived without the benefit of advances in foetal monitoring. The question remains whether they would have been unnecessarily damaged by the birth process. It is difficult to assess what, if any, has been the contribution of the increasing Caesarean section rate to the decrease in perinatal mortality. These two trends, while evident in the countries studied, have not been uniform on an international, or even national scale. Two extreme examples are the USA and Dublin in the Republic of Ireland. While in both countries perinatal mortality rates have dropped during the period 1965-80, Caesarean section rates have soared in the USA but have remained virtually constant in Dublin. ${ }^{52}$ A 50 per cent drop in perinatal mortality over a ten year period associated with only a modest increase in Caesarean section from 8 per cent to 9.9 per cent has been reported from Newcastle, UK. ${ }^{53}$ The correlation between perinatal mortality and operation rates in Europe was reported to be a weak negative one $(r=-0.48)$ indicating that the practice of Caesarean section did not contribute much to the differences in perinatal mortality rates between the countries assessed. ${ }^{54}$ This study suggests that in the Maltese Islands there appears to be no relationship between decreasing perinatal mortality rates and Caesarean section rates greater than 6 per cent. Below this figure, an increasing Caesarean section may or may not have been a contributory factor in the fall in perinatal mortality. The 6 per cent figure is well within the WHO recommendation that "countries with some of the lowest perinatal mortality rates in the world have Caesarean section rates of less than $10 \%$. There is no justification for any region to have a rate higher than $10-15 \% " .55$

The influence of Caesarean section on maternal mortality is less clear, though it appears from the present study that, while freer access to Caesarean section in cases of obstructed labour may have prevented maternal deaths from ruptured uterus, a rise in the Caesarean section rate greater than 2 per cent has little further effect in decreasing maternal mortality. In spite of the reported lower mortality rates resulting from surgery, Caesarean section still carries a definite risk of maternal death and morbidity. In the United Kingdom, the decrease in maternal mortality rates has been shown to be greater than the Caesarean section-related maternal mortality rate. ${ }^{56}$ High on the list of causes of death associated with Caesarean section are thromboembolism and anaesthesia accidents, both of which may be considered as

52 S. F. Bottoms, M. G. Rosen, and R. J. Sokol, 'The increase in the Caesarean section birth rate', $N$. Engl. J. Med., 1980, 302: 559; K. O'Driscoll and M. Foley,'Correlation of decrease in perinatal mortality and increase in Caesarean section rates', Obstet. Gynecol., 1983, 61: 1.

53 J. H. Rizvi and S. R. Chaudri, 'Changing patterns of Caesarean section', Aust. N. Z. J. Obstet. Gynaecol., 1988, 28; 263.

${ }^{54} \mathrm{P}$. Bergsjo, E. Schmidt and D. Pusch, 'Difference in the reported frequencies of some obstetrical intervention in Europe', Br. J. Obstet. Gynaecol., 1983, 90: 628.

55 R. Derom, N. B. Patel and M. Thiery, 'Implications of increasing rates of Caesarean section', in J. Studd (ed.) Progress in obstetrics and gynaecology, Edinburgh, Churchill Livingstone, 1987, pp. 175-94.

56 I. Chalmers, 'Trends and variations in the use of Caesarean section', in J. Clinch and T. Matthews (eds), Perinatal medicine, Lancaster, MTP Press, 1985, pp. 145-9. 


\section{Savona-Ventura}

related to the surgical procedure. Maternal mortality statistics from the Maltese Islands are difficult to assess satisfactorily because of wide annual fluctuations due to the small number of total births which occur on the islands each year. However, the three surgery-related deaths which occurred since 1975 were all directly or indirectly caused by the anaesthetic.

The rise in Caesarean section rates on the Maltese Islands has followed similar trends elsewhere, in line with modern aspects of obstetric practice. The main reasons for the operation in recent years appear to be problems with delivery and foetal considerations. In Dublin, the virtually constant 4-5 per cent Caesarean section rates during the period 1965-80 have been attributed to the strict adherence to the programme of active management of labour. ${ }^{57}$ The term dystocia or abnormal labour is vague, and includes abnormalities related to the birth passages, the foetus, and the labour forces. Misinterpretation of the process of labour often leads to an unwarranted Caesarean section, while termination of labour simply because an arbitrary time is set for the duration of the first and second stage may result in an unnecessary operation. The introduction of labour curves has contributed to early identification of abnormal labour patterns and intervention with oxytocin. This active management of labour has been shown to decrease the need for Caesarean section. ${ }^{58}$ On the other hand, centres which promote the natural process of labour avoiding intervention with oxytocin report Caesarean section rates of about 6-7 per cent, undertaken for conditions such as a brow presentation, transverse lie, cord prolapse, placenta praevia, non-progress with breech presentation, and severe preeclampsia. Such centres report a rate of oxytocin use of less that 1 per cent and a vaginal delivery rate with the use of instruments of 6 per cent. ${ }^{59}$ It is probable that changes in current obstetric practice can reduce Caesarean section rates for dystocia without affecting neonatal outcome.

Caesarean section is an accepted procedure in the event of foetal distress, but the definition of this ambiguous term remains problematic. A distinction must be made between foetal distress and the much more dangerous condition of foetal hypoxia. There can be no doubt that the introduction of electronic foetal heart rate monitoring in labour has resulted in an increase in Caesarean section rates for "foetal distress" in many obstetric units. With increasing experience in the interpretation of such monitoring, the diagnosis of foetal distress is reduced resulting in a corresponding drop in Caesarean operations for this condition. ${ }^{60}$ Concurrent use of foetal scalp blood sampling has enhanced the accuracy of diagnosis of foetal hypoxia and several doctors have reported a decrease in Caesarean section rates after this test was introduced. ${ }^{61}$

Breech presentation is another important reason for undertaking Caesarean section. Breech delivery is associated with a high risk of foetal morbidity and

${ }^{57}$ O'Driscoll and Foley, op. cit., note 52 above.

58 Ibid.

${ }^{59} \mathrm{M}$. Odent, Birth reborn. What birth can and should be, London, W. Clowes, 1984.

${ }^{60}$ R. Neutra, S. Greenland and E. A. Friedman, 'Effects of fetal monitoring on cesarean section rates', Obstet. Gynecol., 1980, 55: 175.

${ }^{61}$ M. Pillai, 'Fetal monitoring during labour', Br. med. J., 1984, 288 : 67. 


\section{Caesarean section in the Maltese Islands}

mortality, and Caesarean section has been advocated in the majority of cases. ${ }^{62}$ After further experience and studies, it has been suggested that, provided certain conditions are fulfilled, a considerable number, probably more than 50 per cent of breech presentations, can be safely delivered vaginally. ${ }^{63}$ Multiple gestation has also been associated with changing trends in Caesarean section rates, probably because of the high incidence of premature births and breech presentations in twin and triplet pregnancies, both of which are considered by many doctors as contra-indications for vaginal delivery. The role of Caesarean section in reducing foetal mortality and morbidity in multiple births remains questionable. ${ }^{64}$ The fear of malpractice suits, and the increased problems of maternity care, may result in precautionary obstetrics being practised if there is any indication of foetal risk, however minimal.

Active efforts must be undertaken and maintained by every maternity unit to keep Caesarean section rates to a safe minimum of about 10-15 per cent as advocated by the WHO. ${ }^{65}$ This can be achieved only by ensuring that well-trained personnel are present continuously in the labour ward, and that a constant monitoring of maternity care includes not only an examination of perinatal morbidity and mortality cases, but also an assessment of the reasons for undertaking Caesarean sections.

${ }^{62}$ F. Kubli, W. Boss and H. Ruttgers, 'Caesarean section in the management of singleton breech presentation', in G. Rooth and L. E. Bratteby (eds), Perinatal medicine, Stockholm, Almqvist and Wiksell, 1976, pp. 69-75.

${ }^{63}$ Derom, et al., op. cit., note 55 above.

${ }^{64}$ A. Loucopoulos and R. Jewelwicz, 'Management of multifetal pregnancies: sixteen years experience of the Sloan Hospital for Women', Am. J. Obstet. Gynecol., 1982, 143(8): 902.

${ }^{65}$ Derom, et al., op. cit., note 55 above. 